\title{
RESENHA
}

\section{BRANQUITUDES: UM ESTUDO SOBRE RELAÇÕES RACIAIS EM} SÃO PAULO

\author{
BLANQUITUDES: UN ESTUDIO SOBRE LAS RELACIONES RACIALES EN \\ SÃO PAULO
} WHITENESS : A STUDY ON RACIAL RELATIONS IN SAO PAULO

\section{Resenha de:}

Schucman, L. V. (2014). Entre o encardido, o branco e o branquissimo: branquitude, hierarquia e poder na cidade de São Paulo. São Paulo: Annablume.

Lia Vainer Schucman graduou-se em Psicologia em 2003, pela Universidade Federal de Santa Catarina, concluiu o mestrado em 2006 na mesma universidade e doutorou-se pela PUC de São Paulo em 2012, com tese homônima ao livro aqui resenhado. Além disso, tem larga experiência como pesquisadora inclusive em universidades norte-americanas, como a Universidade da Califórnia. Atualmente é bolsista da FAPESP, onde realiza trabalho de pesquisa sobre famílias interraciais.

A presente obra é resultado da tese de doutorado de Schucman. A apresentação de Leny Sato, exorientadora da autora, e o prefácio de Maria Aparecida Silva Bento já dizem a que o livro veio. Leny aponta para o cuidado com que a autora "escuta" as vozes do cotidiano, inclusive sua capacidade de se localizar nessa mesma sociedade, sobre a qual ela faz sua análise, a partir de sua condição como pessoa branca, mulher de uma família paulistana. Já Maria Aparecida aponta para a importância desse trabalho no momento em que, pela primeira vez, a sociedade brasileira assume que existe racismo em seu interior e quando os movimentos sociais exercem um papel fundamental, pressionando para incrementar políticas públicas visando à igualdade racial.

Antes dos capítulos que se referem ao tema estudado, a autora faz uma breve apresentação de seu trabalho, fruto de sua tese de doutorado defendida em 2012, na Universidade de São Paulo (USP). Nessa introdução, intitulada "Rompendo o pacto racista: colocando o branco em questão", são expostos os motivos que a levaram a discutir tal temática. Ela se coloca no campo da psicologia social, politicamente engajada com as transformações sociais em nosso país, fruto principalmente da chamada psicologia social crítica originária no Brasil principalmente na década de 80. Mas isto apenas não basta. Ela sensivelmente se posiciona. E o faz de uma maneira interessante, reconhecendo-se em todas as categorias possíveis que sua compreensão delimitou, como mulher, branca, de classe média e descendente de judeus. Ou seja, as reflexões sobre racismo e suas consequências perpassaram sua existência. Essa mesma mobilização fez Jean-Paul Sartre escrever um de seus livros clássicos, Reflexões sobre o racismo, de 1968. Schucman problematiza, de forma interessante, as razões para que, mesmo com uma posição menos "conservadora", as famílias brancas não percebam o negro de maneira integral, como sujeito íntegro de direitos e pertencente ao seu círculo pessoal e de amizade legítimo, mas como alguém digno de "caridade" (p. 25) ou que necessita de "favores" (p. 25). Há em seu trabalho um propósito corajoso e audacioso: denunciar o que ela chama de "privilégios simbólicos" (p. 25), que existem em uma cultura simbolicamente feita para brancos. A autora deixa presente que sua proposta é discutir como a branquitude constitui e é apropriada pelos sujeitos de suas entrevistas, habitantes da cidade de São Paulo.

A obra se divide em sete partes: a primeira intitula-se "Notas Sobre a pesquisa"; a segunda, "Branquitude"; a terceira, "Raça e racismo"; a quarta, "A construção da branquitude na cidade de São Paulo"; a quinta, "Aspectos psicossociais da branquitude paulistana"; a sexta, "Fronteiras e hierarquias internas da branquitude", e, por último, "Fissuras entre a brancura e a branquitude: possibilidades para a desconstrução do racismo". 
No capítulo intitulado "Notas sobre a pesquisa", Lia apresenta sua perspectiva metodológica, partindo da ideia de microlugares e de cotidiano e da ideia de "campo tema", com a perspectiva pós-construcionista de Peter Spink. Aqui vale a pena ressaltar uma relação muito próxima com as discussões da antropologia social de Clifford Geertz e sua obra $A$ interpretação das culturas (1989), na qual ele aponta para o campo da cultura como "rede de significado" que está presente no cotidiano. Além da entrevista, empregando os procedimentos de observação e com seu diário de campo, a autora foi desnudando aquilo que se faz no cotidiano de um país que, apesar de se pensar democrático racialmente, tem dificuldades em aceitar sua própria cor. Por meio das piadas, das conversas nos cafés e festas, da própria universidade, ela foi tomando nota do Brasil que não se quer perceber... Ou ainda, parafraseando Jurandir Freire e Costa, o Brasil que não ousa olhar sua cor.

Durante as conversas informais, chamaram sua atenção alguns fatos, como, por exemplo, a dificuldade de brancos se entenderem como tais, quando perguntados sobre sua raça, enquanto os negros rapidamente o faziam a partir da sua autoidentificação com a sua cor de pele. A autora problematizou o fato de ser branca e estar pesquisando os brancos, o que colocou os entrevistados em uma posição confortável para dizerem o quanto se sentiam muitas vezes "desprivilegiados" com as políticas de ação afirmativas ou ainda outras "vantagens" que os negros supostamente estavam tendo no mundo contemporâneo.

No capítulo 2, "Branquitude", a autora discute sobre o branco e o seu lugar nas relações raciais. Segundo ela, esses estudos foram iniciados na década de 90, nos Estados Unidos. Aqui fica presente a perspectiva de apresentar a branquitude como um aspecto ideológico que transforma uma característica fenotípica em relação de hierarquia e poder, e que acontece de uma maneira transnacional, principalmente por meio dos choques culturais entre continentes como Europa, América e África. A autora pontua algo muito importante: discutir as relações raciais sem problematizar o branco nesta relação é reafirmar sua superioridade racial frente aos negros. Isso porque, se entendermos que os problemas decorrentes das relações raciais são "relacionais", ambos estão envolvidos nesta problemática. Ainda nesse capítulo, ela relata que a construção da branquitude como privilégio foi construída no início do século XX entre trabalhadores do sul dos Estados Unidos, através de uma "facilitação" maior para os brancos trabalhadores do que para os negros do mesmo status. Ou seja, mesmo estando em condições muito precárias através do trabalho, ser branco garantiu para muitos trabalhadores poder galgar lugares sociais mínimos, mas melhores em relação aos negros. Assim, aos poucos a branquitude foi se garantindo como um privilégio nos Estados Unidos e, por isso, uma causa que era comum a todos - como melhores condições de trabalho - foi desaparecendo, à medida que brancos e negros se distanciavam identitariamente, uma ótima discussão para as teorias sobre identidades. Ser trabalhador e ter péssimas condições de vida foi construído identitariamente como algo menos importante do que a cor da pele daqueles que compartilhavam as mesmas condições! Além disso, nesse capítulo é feita uma apresentação muito didática do clássico texto de Franz Fanon (2008), Pele negra, máscaras brancas, no qual aparece a tese principal deste importante autor dos estudos pós-coloniais. Para a autora, um elemento importante da branquitude no Brasil é que, mais do que aos aspectos genéticos, a branquitude está atrelada "ao status e ao fenótipo", que garantem privilégios e passagem livre em determinados lugares. A discussão da autora destaca a invisibilidade do branco, que passa a ser compreendido como ser "universal" e genérico; as comparações partem dele e de sua visibilidade, quando faz jus ao seu lugar de sujeito privilegiado e que pode obter condições melhores graças à sua branquitude.

No capítulo 3, intitulado "Raça e racismo", a autora discorre sobre esses dois conceitos, apontando que o conceito de raça apresenta relação direta com o tempo histórico, principalmente atrelado às grandes descobertas e viagens do século XV. Tais estudos, segundo Schucman, se dividiram entre "monogenistas" e "poligenistas". Os primeiros consideravam que existiria uma graduação do ser humano, que culminaria com um ser "perfeito". A partir das teorias de Darwin, muito mal aplicadas às ciências humanas por sinal, o monogenismo foi a explicação plausível para as diferenças humanas. Já o poligenismo defendia a ideia de diferentes origens para os seres humanos, sendo que é dessa vertente que surge a ideia de raça. Tanto um quanto o outro partiram de ideias evolucionistas. Isso acabou criando uma hierarquia, primeiro pela cor da pele, depois por traços fisionômicos. Nesse grupo, os brancos sempre se encontraram privilegiados como um modelo superior de evolução. Tal processo, segundo a autora, foi ideologicamente importante para justificar a escravidão dos povos africanos.

A autora aponta de modo contundente a forma ideológica como este processo se deu. Apesar de não conceituar claramente o que entende por ideologia, suas colocações se posicionam como uma estratégia de dominação europeia sobre outros povos, no caso 
os africanos. Ela ainda precisa que a ideologia racista foi fundamental para as políticas imperialistas do capitalismo atual.

A autora faz suas reflexões não sem passar também por Michel Foucault, autor bastante conhecido no campo da Psicologia Social no Brasil. Ela o faz a partir de um dos seus conceitos mais utilizados: o "biopoder". Para ela, o racismo aliado ao biopoder deu possibilidades de verdadeiros massacres da população afrodescendente lançada à "exclusão".

Um dos pontos mais interessantes desse capítulo é sua discussão sobre o conceito de raça empregado na atualidade e suas implicações. Tanto que a autora faz questão de dizer que utiliza o termo "raça social", ou seja, a discussão parte das implicações sociais da desigualdade entre negros e brancos, tendo principalmente as características fenotípicas como objeto de análise e observação. Ela aqui dá o exemplo das políticas de cotas baseada em duas vertentes: a dívida social dos povos brancos para com os povos afrodescendentes e a construção de uma identidade racial de negros, devido à positividade que essas políticas têm propiciado com a possibilidade de mobilidade social deste grupo. Mas ela também relata que existem tensões entre estudos acadêmicos sobre as diferenças raciais e o que pensam alguns teóricos e movimentos sociais sobre o mesmo tema. Ainda não existe um consenso sobre o assunto. Mesmo assim, conforme a autora, não restam dúvidas entre os intelectuais brasileiros: existe racismo no Brasil!

Neste capítulo a autora também explana didaticamente muito bem sobre como se constitui o sistema racista brasileiro e seus efeitos, a partir da ideia muito disseminada e consolidada sobre a "democracia racial". Schucman aponta ainda que, de forma diferente dos Estados Unidos, a discriminação racial se dá pela via das características fenotípicas negras no Brasil e se atualiza e se mascara de diversas formas - desde a individualização dos processos de exclusão dos sujeitos negros, até a culpabilização daquilo que poderíamos chamar de uma "cultura da pobreza", ou seja, negros não são discriminados pelo racismo, mas sim por serem pobres, o que ressalta mais uma vez a ideia de uma democracia racial brasileira.

No capítulo 4, intitulado "A construção da branquitude na cidade de São Paulo", Schucman relata os dados de sua pesquisa em São Paulo. Apesar de ser focalizada, nem por isto o texto deixa de trazer reflexões importantes sobre a situação do racismo e da branquitude no Brasil. Com uma breve, mas muito interessante história do crescimento da cidade de São Paulo, é mostrada a importância dos negros escravos como elemento fundamental para o crescimento econômico da cidade. Aqui a autora traz informações importantes para a compreensão do chamado branqueamento; não que este seja novidade no campo das ciências sociais, mas no campo da psicologia social, ela o discute e faz um verdadeiro "escrutínio" deste conceito. Bem articulado e fundamentado, mostra como o branqueamento é constituidor daquilo que podemos chamar de privilégio por ser "branco" neste país. De forma muito didática e através de imagens, a apresentação de mapas coloridos mostra uma relação entre áreas de maior desenvolvimento humano (IDH) e populações brancas e áreas de menor IDH e ocupadas por populações afrodescendentes. Fica nítida a relação entre vulnerabilidades: bairros com maiores populações negras e menor renda familiar e, de outro lado, bairros considerados nobres, com uma população com maior renda e maior número de pessoas brancas.

No capítulo "Aspectos psicossociais da branquitude paulistana", a autora aponta como a miscigenação e a mestiçagem se relacionam com os sujeitos considerados brancos na capital paulista. Neste capítulo a autora faz um levantamento sobre o modo como os seus entrevistados se posicionam frente a sua brancura. O que pensam dela? Como a utilizam na relação com o mundo? Por meio de suas entrevistas, realizadas muito objetivamente, informa a classificação que brancos "sentem" em relação à negritude alheia. Através de relatos precisos, as posturas dos entrevistados vão revelando o que os brasileiros pensam da "contradição" das cores em nosso país. A autora vislumbra como os sujeitos não negros se percebem como sendo, de alguma forma, superiores aos sujeitos negros. Aqui ficam explícitas as contradições postas na subjetividade social brasileira. Reconhecer que existe racismo e desigualdade é uma coisa, envolver-se para que esta mesma diminua ou desapareça, com certeza é muito mais difícil.

No capítulo 6, intitulado "Fronteiras e hierarquias internas da branquitude", a autora propriamente discute a identidade racial e a desigualdade social atrelada a ela. Citando Joan Scott, o tom do capítulo é dado de maneira muito interessante, quando se abre com uma epígrafe - "o verdadeiro antônimo da igualdade é a desigualdade" - e dá o exato teor de seu escrito. Ela discute esta categoria a partir da psicologia sócio-histórica que é sua perspectiva teórica bem demarcada desde o início do texto. Deixando presente que existem sempre múltiplas classificações mesmo entre as identidades, a autora problematiza como estas se estruturam na relação com a identidade racial. Relata que mesmo sujeitos que se compreendem como brancos, quando comparados com outros que possuem 
traços fenotípicos mais brancos que eles, acabam sendo considerados mais "sujinhos" - expressão de uma de suas entrevistadas. Ou seja, um branco menos europeu, mais mestiço. Uma classificação dentro de outra. Segundo a autora, há uma hierarquia de poder através dos fenótipos existentes entre os mais brancos e, consequentemente, também entre os mais "escuros". A autora aqui entrecruza as categorias como raça e gênero, tocando em aspectos pertinentes como as relações inter-raciais e problematizando-as dentro da hierarquização social descrita no capítulo. É interessante perceber que, para os seus entrevistados brancos, esta identidade está atrelada ao status social elevado, ou seja, "branquíssimos" se consideravam aqueles que possuíam "dinheiro, posses e status social".

No seu capítulo final, intitulado "Fissuras entre a brancura e a branquitude: possibilidades para a desconstrução do racismo", que serve também como as considerações finais, são trazidas reflexões sobre possibilidades de intervenção a respeito da temática. A partir de Vigostky, e uma leitura da Psicologia Histórico-Cultural, muito pertinente para a Psicologia, ela levanta elementos importantes para a discussão da subjetividade nas relações raciais. Como questão mais importante sobre as possibilidades de intervenção sobre o racismo, é trazida a antropóloga afro-americana France Winddance Twine, a qual revela que uma das possibilidades concretas para a desconstrução do racismo é que os brancos também se percebam de maneira racializada e que assim tenham capacidade de realizar a leitura do mundo social que os cerca e de como eles interagem com este mundo.

Talvez a principal das contribuições desta obra esteja no trabalho de trazer a reflexão e discussão, no interior da psicologia, a respeito das relações raciais sob o prisma do embranquecimento. Isto porque como toda ciência, ou quase toda, a Psicologia se constituiu como uma ciência branca, pensada de maneira hegemônica e normatizante que, quando se lança a discussões como esta, sempre traz em seu bojo expressões como "precisamos discutir isto? Se as pessoas são todas iguais...". Lia apresenta muito bem que não somos iguais, muito menos tratados como se fôssemos. Obra fundamental para psicólogos iniciantes, mas também e principalmente - veteranos!

Tristemente podemos aqui, depois de ler a obra, parafrasear uma conhecida música do compositor Seu Jorge, que diz: "A carne mais barata do mercado é a carne negra..." Se essa é a mais barata, com certeza a carne mais cara do mercado é a carne branca. Esperase que, com obras como esta, isto não seja para sempre.

\section{Referências}

Fanon, F. (2008). Pele negra, máscaras brancas. Salvador: EDUFBA.

Geertz, C. (1989). A interpretação das culturas. Rio de Janeiro: Guanabara Koogan.

Sartre, J. P. (1968). Reflexões sobre o racismo. São Paulo: Difusão Europeia do Livro.

Submissão em: 22/10/2015

Aceite em: 06/12/2015

Leandro Castro Oltramari possui graduação em Psicologia pela Universidade do Vale do Itajaí (1997), mestrado em Psicologia pela Universidade Federal de Santa Catarina (2001) e doutorado em Interdisciplinar em Ciências Humanas pela Universidade Federal de Santa Catarina (2007). Atualmente é professor adjunto I da Universidade Federal de Santa Catarina. Participante do Grupo de pesquisa Psicologia e Processos Educacionais.

Endereço: PPGP-CFH-UFSC. Campus Universitário. Trindade. CEP 88040-970. Florianópolis/SC, Brasil.

E-mail: leandrooltramari@gmail.com 